American Journal of Applied Sciences 4 (4): 192-196, 2007

ISSN 1546-9239

(C) 2007 Science Publications

\title{
Income Distribution and Health Status: Econometric Evidence from OECD Countries
}

\author{
Vasudeva N.R. Murthy \\ Economics and Finance Department, College of Business Administration \\ Creighton University, 2500 California Plaza, Omaha, NE 68178
}

\begin{abstract}
This research note, using a cross-sectional sample consisting of 27 Organization for Economic Co-operation and Development countries (OECD) for the reference year 2002, empirically examines the relationship between health status as measured by infant mortality and the degree of income inequality, given the effect of certain controlled variables. The empirical findings based on the estimation by robust econometric methods, show that in these countries, per capita real gross domestic product, the number of doctors, the level of education, percentage of female smokers in the adult population and income inequality, as reflected by the percentage of the income received by the lowest tenth of the population do impact the level of health status. The results clearly indicate that income inequality affects the level of health status adversely. Policy implications of the research findings are discussed in the research.
\end{abstract}

Keywords: Income inequality, infant mortality and robust regression

\section{INTRODUCTION}

In recent years, economists, health experts and health policy makers have been interested in understanding why some countries and societies enjoy better health status as reflected by prolonged life expectancy and lower infant mortality. Equity in health has been extensively discussed by health scholars $^{[2,4 \cdot 10,15,22]}$. Knowledge of the main determinants of health status and their quantitative impact aids in the formulation of effective policies aimed at enhancing the level of health status in both developed and developing countries. One of the important factors, both at the individual and aggregate level that has been theoretically identified is the degree of income inequality. In the literature, it has been shown theoretically and empirically, that health status is not only being influenced by the level of absolute income, but also by the relative income ${ }^{[1,8,13,14,16,17,24-26]}$. Also, in the literature, while most of the studies were undertaken by using the correlation analysis, in this research note regression analysis is employed. While the absolute income hypothesis contends that the higher the level of an individual's per capita real income, the better his or her health status, the relative income hypothesis states that an individual's health status is influenced adversely by the degree of income inequality within the economy. Income inequality is said to affect health status inversely, given the effects of other determinants. The main objective of this research note is to estimate the impact of income inequality on heath status, employing Ordinary Least Squares (OLS) method, for the reference year 2002, utilizing the most recent and relevant data on a cross-section of 27 , both the original and newly ratified Organization for Economic Cooperation and Development (OECD) countries. The countries that are included in the study are Australia, Austria, Belgium, Canada, Czech Republic, Denmark, Finland, France, Germany, Greece, Hungary, Ireland, Italy, Japan, Korea, Mexico, Netherlands, Poland, Portugal, Slovia Republic, Spain, Sweden, Switzerland, Turkey, United Kingdom and United States of America. In the literature, there have been empirical attempts to measure the relationship between income inequality and population average health status, called the "concavity effect" and the effect of income inequality per se, on health status, referred to as the "pollution effect" Strictly speaking, to quantify the impact of the above mentioned effects, one needs to conduct a multilevel analysis. The multilevel analysis is not undertaken here due to paucity of data on health status and income at both individual and aggregate levels in the countries studied. The measure of income inequality that is used for empirical estimation in this research note is the share of income received by the lowest 10 percent of the population (LTNPRD). The incorporation of some
Corresponding Author:

Vasudeva N.R. Murthy, Ph.D., Economics and Finance Department, College of Business Administration, Creighton University, 2500 California Plaza, Omaha, NE 68178, Tel: 4022802112, Fax: 402280-5565 
control variables in the specified model that were not considered in similar studies and the employment of a robust econometric estimating technique, such as the Least Absolute Error Estimator (LAE), is highly warranted in the presence of outliers. It is widely known in the econometric literature, that outliers can have a substantial influence on both the parameter estimates and their standard errors in a regression model. Specifically the research note has estimated the impact of income inequality on the level of health status, as measured by infant mortality (INFMR), given the following control variables: the per capita real GDP (INCOME), the number of physicians (DOC), the level of education (EDU) and the percentage of female smokers in adult population (SMOKFL).

The model, methodology and data: A literature survey of the determinants of health status in developed countries and the availability of data has dictated the specification of the following double-logarithmic econometric model:

$\ell n H S T A T U S=\ell n b_{1}+b_{2} \ell n I N C O M E+b_{3} \ell n I N C I N E Q+b_{4} \ell n D O C$

$$
+b_{5} \ell n E D U+b_{6} \ell n S M O K F L+\mu
$$

where HSTATUS, INCOME, DOC, INCEQ, EDU and SMOKFL are, the infant mortality rate, real GDP per capita, the number physicians per 1,000 persons, a measure of income inequality, net secondary school enrollment rate as a percent of relevant age group and the percentage of female smokers in the adult population, respectively. The income inequality measure used in the estimation of the equation (1) is the share of income received by the lowest 10 percent of the population (LTNPCRD). The other measure of income inequality, the Gini coefficient is not used here because a recent study reports results using an exact specification with the GINI coefficient as a measure of income inequality and arrives at basically similar findings ${ }^{[16]}$. According to the theoretical criteria, in equation (1), the expected signs of the regression coefficients, $b_{2}, b_{4}$ and $b_{5}$ are negative and the sign of the regression coefficient, $b_{6}$ is positive. The expected sign of the coefficient of the variable of income inequality, $b_{3}$ is negative. An increase in LTNPCRD reflects an improvement in the distribution of income. In equation, $\mu$ is the stochastic term that is expected to be normally distributed and homoskedastic. In the specified model, the mathematical form of equation (1) has the added mathematical advantage of considering any non-intrinsic non-linear functional relationship among the dependent and the explanatory variables and yielding the coefficient estimates as the respective elasticities of health status with respect to the independent variables.
Theoretically, health status is influenced by the level of absolute income (INCOME), because higher level of income leads to a greater ability to afford better medical attention, nutrition, sanitation, housing and healthcare ${ }^{[29,32,33]}$. Some economists contend that higher income enhance technological progress in health care and dissemination of knowledge pertaining to new medical technology ${ }^{[31]}$. It has been observed by labor economists that at low levels of income, there is often a high rate of absenteeism among workers as they suffer from frequent illness due to malnutrition and lack of preventive care. Since healthcare is either a normal good or a luxury good in the OECD countries studied, implies that health care spending is being driven by the ability to pay ${ }^{[3,9,18,20]}$. While income plays an important part in determining a person's health status, it alone cannot explain a considerable amount of variation in the level of health status ${ }^{[1]}$. There are cases of some low income countries where the average health status as measured by infant mortality and life expectancy is high and cases of some high income countries that do not enjoy a very high level of health status ${ }^{[1]]}$. Relative income (INCINEQ) is also said to adversely impact the health status of a person. In the literature, it has been contended that income distribution affects an individual's health status ${ }^{[1,17,11,14,26]}$. It has been observed that income inequality as denoted by a lower LTNPCRD and the percent of income spent on education are negatively correlated leading to disinvestment in education. Income inequality might cause a poorer person to develop a negative perception of his or her social status resulting in lower overall health status ${ }^{[7,2,25]}$. For instance, pregnant women from low income groups may not seek proper medical attention during pregnancy. Perception of being at the bottom of income distribution might also result in frustration and erosion of "social capital", such as reduced social cohesion, less trust and a lower propensity to participate in community activities ${ }^{[7,11]}$. Another possible determinant of health status is the number of physicians per persons or the physicians' density (DOC). It is hypothesized that the greater the physicians' density, the better the health status, as having more physicians means better access to healthcare, better preventive healthcare and reduced waiting for medical attention. In the economic development literature, it has been observed that in developing countries and in rural areas of developed countries, where the number of physicians per population is low, infant mortality incidence is high and life expectancy is low.

An additional factor that is expected to affect the level of health status is the level of education of the 
Am. J. Applied Sci., 4 (4): 192-196, 2007

population. Theoretically, the level of education (EDU) is expected to exert a positive impact on health status, although some existing empirical studies report contradictory results ${ }^{[17]}$. As the level of education increases, the extent of health-related awareness, such as sanitation, nutrition and understanding risky behaviors such as smoking and preventive care, will be greater and lead to better health outcomes. Furthermore, educated economic participants will practice better preventive healthcare because they can better assess the high opportunity cost of getting sick.

Finally, the specified equation (1) considers the effect of a single but important health risk behavior, cigarette smoking among women (SMOKFL). It is postulated that the larger the percentage of female smokers in the adult population, the higher the infant mortality rate and therefore the lower the health status. The lack of data on smoking among females of child bearing cohort has precluded using that variable.

The data used for estimating equation (1) are obtained from World Development Indicators (2004; 2005) and 2005 OECD Health Data $(2005)^{[27,28]}$. Equation (1) will be first estimated using OLS. The results will be tested for the presence of homoskedasticity and normality. Furthermore, since in this research note we estimate a model that utilizes international cross section data, there is a potential for the presence of outliers. Therefore, a robust estimator as the Least Absolute Estimator Error (LAE) will be employed to estimate the coefficients of the specified regression equation (1). Construction of an econometric model, using panel unit root testing and cointegration procedure is not attempted as the data on all the pertinent variables for all the OECD countries over a long period are not available. The usual assumption that the cross-sectional sample is indicative of the long-run information is made in this research.

\section{RESULTS AND DISCUSSION}

The results of the OLS estimation of equation (1) are reported in Table 1, as model (2). The estimated model (2) is highly consistent in terms of the signs and statistical significance and satisfying econometric assumptions. The observed adjusted $\mathrm{R}^{2}$ and the computed F-statistic indicate that the explanatory variables as a group, in model (2), is statistically significant at the $1 \%$ level, explaining about $92 \%$ of the variation in the dependent variable. These results show that the income inequality measure and the control variables, INCOME, DOC, EDU and SMOKFL do contribute as a group to a respectable amount of variation in the dependent variable, HSTATUS. As the
Table 1: Regression results: OLS estimates: Dependent variable: HSTATUS

\begin{tabular}{lll}
\hline & Model (2) & \\
Variable & Coefficient & $t$-Statistics \\
\hline Constant & 11.718 & $19.526^{*}$ \\
INCOME & -0.413 & $-3.589^{*}$ \\
LTNPCRD & -0.441 & $-4.585^{*}$ \\
DOC & -0.379 & $-4.816^{*}$ \\
EDU & -1.301 & $-5.853^{*}$ \\
SMOKFL & 0.248 & $4.623^{*}$ \\
R-Bar squared $=0.92$ & & \\
F-Stat: $\mathrm{F}=63.12[0.0]^{*}$ & & \\
JB $=0.78[0.68]$ & & \\
$n R^{2}=4.48[0.92]$ & & \\
$\mathrm{N}=27$ & &
\end{tabular}

Notes: a Computed from using the White heteroskedasticity-consistent standard errors. *Indicates significance at the $1 \%$ level. The observed $\mathrm{p}$-values are reported within brackets.

Table 2: Regression results: LAE estimates: Dependent variable: HSTATUS

\begin{tabular}{lll}
\hline & Model (3) & \\
Variable & Coefficient & $t$-Statistics \\
\hline Constant & 11.540 & $133.1^{*}$ \\
INCOME & -0.423 & $-41.71^{*}$ \\
LTNPCRD & -0.396 & $-38.51^{*}$ \\
DOC & -0.372 & $-35.07^{*}$ \\
EDU & -1.252 & $-44.39^{*}$ \\
SMOKFL & 0.249 & $34.02^{*}$
\end{tabular}

Note: *indicates statistical significance at the $1 \%$ level.

sample in the empirical analysis of the research includes countries of different sizes, unknown forms of heteroskedasticity might be present. To handle this phenomenon, $t$-values are computed using the White's heteroskedasticity - consistent standard errors. Furthermore, to detect the presence of heteroskedasticity of an unknown form, the White test is conducted. In model (2) the observed White test statistic, $\mathrm{nR}^{2}$, is less than the critical value with 6 degrees of freedom and therefore, the null-hypothesis of homoskedasticity is not rejected. To test for the presence of normality of the residuals and the dependent variable in model (2), the Jarque-Bera (JB) test for normality is conducted. Since the observed value of the JB statistics is less than the $5 \%$ critical value from a chi-square distribution with 2 degrees of freedom, the evidence fails to reject the null hypothesis of normality.

The coefficient of INCOME in model (2) is statistically significant at the $1 \%$ level indicating that income does play an important role in explaining variation in health status among the countries included in the study ${ }^{[29,31,32,33]}$. This result shows that as income increases, infant mortality decreases and this effect 
leading to an improvement the level of health status. This finding is consist with those found by Preston and Pritchett and Summers ${ }^{[29,32]}$.

In the estimated model (2), the coefficient of LTNPCRD displays the hypothesized, negative sign and is statistically significant at the $1 \%$ level. The observed negative sign of the coefficient of LTNPCRD, in model (2), shows that as the degree of income inequality improves with the lowest ten percent of population receiving more income, infant mortality decreases, amounting to a better health status outcome.

In model (2), the DOC variable displays a negative sign, indicating that as the number of physicians increases, infant mortality decreases. This result suggests that increased number of physicians per 1,000 persons results in both extensive and intensive medical attention and care leading to enhanced preventive care and better monitoring of illness and thus an ultimate reduction in infant mortality. It is also very clear from the results of model (2) that education plays an important role in reducing infant mortality and therefore leads to a better health status. The coefficient of EDU, besides being relatively large, is statistically significant at the $1 \%$ level.

This finding reinforces the theoretical notion that people with more education understand the importance of the timely medical attention, are able to acquire more health-related information and furthermore, they properly evaluate the opportunity cost of their time and therefore would practice effective preventive care and seek immediate medical attention. Finally, the coefficient of the SMOKFL variable in model (2) is positive and statistically significant at the $1 \%$ level, suggesting that health risk behavior of people is one of the important determinants of health status. This result shows that as the percent of female smokers in the adult population increases, the rate of infant mortality increases.

Since the sample used for estimation of model (2) consists of countries of differing sizes and institutions, the presence of outliers in the data sample is imminent. It has been shown in the literature that the presence of outliers causes the coefficient magnitudes and signs to be very unstable and the standard errors of the regression coefficients to be higher. Therefore, in order to correct for the presence of outliers, a robust estimator, the Least Absolute Estimator Errors (LAE), is employed to estimate model (3). The LAE "down weights" the influence of outliers and yields robust estimates of standard errors of regression coefficients, that are not sensitive to extreme observations. Therefore, there is an imminent possibility of gaining efficiency in terms of very high t-values. The results are reported in Table 2. It is evident that the results presented in Table 2 are highly consistent in terms of signs, magnitudes and statistical significance with those reported in Table 1, derived from the OLS estimation. The findings, besides indicating the presence of some influential observations in the data sample, reinforce the finding that given the effects of the controlled variables, the degree of inequality does affect the level of health status adversely in OECD countries during the reference period.

\section{POLICY IMPLICATIONS AND CONCLUSION}

This research note, utilizing the most recent crosssectional data on a sample of 27 OECD countries, has empirically determined the effect of the degree of income inequality, as measured by the share of income received by the lowest ten percent of the population, on the level of health status. Controlling the effects of level of absolute income, the density of physicians, the level of education and the percentage of female smokers in adult population, increased income inequality in OECD countries, results in an adverse effect on health status. Increased income received by the lowest ten percent of the population reduces infant mortality. The policy makers in the OECD countries, who are concerned with the goal of health equity, can improve the health status by increasing the level of per capita real income, the number of physicians and the level of education and by decreasing the percentage of female smokers. Health status can be improved by reducing the overall inequality in income via effective income redistributive policies.

Through health scare and anti-smoking educational campaigns, policy makers and World Health Organizational agencies can attempt to reduce the percentage of female smokers in the population. Finally, by facilitating investment in human capital in the long-run in general and medical education in particular, the policy makers can contribute to an enhanced health status in these countries.

\section{ACKNOWLEDGEMENTS}

This research note is a revised version of an earlier paper presented at the Academy of Economics and Finance Meeting, 2005. The author is grateful to Professor William H. Sackley of the University of North Carolina at Wilmington for his valuable comments and suggestions. 


\section{REFERENCES}

1. Adjaye, J.A., 2004. Income inequality and health: A multi-country analysis. Intl. J. Soc. Econom., 31: 195-207.

2. Cutler, D., A. Deaton and A. Lleras-Muney, 2005. The determinants of mortality. Working Paper of the Department of Harvard University, Woodrow Wilson School and Department of Economics, (December) Princeton University, Princeton, NJ.

3. Culyer, A.J.,1988.Health Expenditure in Canada, Myth and Reality: Past and Future. Canadian Tax Foundation Paper 82, Canadian Tax Foundation, Toronto, Canada.

4. Deaton, A., 1999. Inequalities in income and inequalities in health. Working Paper of the Research Program in Development Studies, (May) Princeton University, Princeton, NJ.

5. Deaton,A., 2001. Relative deprivation, inequality, and mortality. Working Paper of the Research Program in Development Studies \& Center for Health and Wellbeing (January),Princeton University ,Princeton, NJ.

6. Deaton , A., and Lubotsky,2002. Mortality, inequality and race in American cities and states. Working Paper of the Center for Health and Wellbeing (February),Princeton University, NJ.

7. Dressler, W.W., 1996. Culture and blood pressure: Using census analysis to create a measurement. Cultural Anthropolgy Methods, 8:6-8.

8. Dressler, W.W., M.C. Baliero and J.E. Dos Santos, 1999. Culture, skin color,and artificial blood pressure in Brazil . American Journal of Human Biology ,11: 49-59.

9. Gerdtham, U.G. and B. Jonsson, 2000. International Comparisons of Health Expenditure: Theory and Econometric Analysis. In: Handbook of Health Economics (Eds. A.J. Culyer and J.P. Newhouse). Amsterdam: North-Holland.

10. Judge, K., 1995. Income distribution and life expectancy: A critical appraisal. Br. Med. J., 311: 1282-1285.

11. Kawachi, I., B.P. Kennedy, K. Lochner and D. Prothow-Stith, 1997. Social capital, income inequality and mortality. Am. J. Public Health, 87: 1491-1498.

12. Kawachi, I., and B.P. Kennedy,1999. Income inequality and health:Pathways and mechanisms. Health Services Research,34: 215-227.

13. Lochner, K., D. Makuc, B.P. Kennedy and I. Kawachi, 2001. State level income inequality and individual mortality risk: A perspective, multilevel study. Am. J. Public Health, 91: 351-353.

14. Lynch, J.W. and G.A. Kaplan, 1997. Understanding how inequality in the distribution of income affects health. J. Health Psychol., 2: 297-314.
15. Macinko, J.A. and B. Starfield, 2002. Annotated bibliography on equity in health 1980-2001. Intl. J. Equity in Health, 1: 1-20.

16. Murthy, N.R.V., 2006. Income distribution and health status: Evidence from OECD countries, Atlantic Economic Journal

17. Muller, A., 2002. Education income inequality and mortality: A multiple regression analysis. Biomed. J., 324: 23-25.

18. Newhouse, J.P., 1977. Medical care expenditure: A cross-national survey. J. Human Resources, 12: $115-125$.

19. OECD, 2005. OECDHealth Data 2005. OECD, Paris,

20. Okunade, A.A. and N.R.V. Murthy, 2002. Technology as a 'major driver' of health care costs: A cointegration analysis of the newhouse conjecture. J. Health Economics, 21: 147-159.

21. Rodgers, G.B., 2002. Income and income inequality as determinants of mortality: An international cross-section analysis. International Journal of Epidemiology, 31: 533-538.

22. Subramanian, S.V., P. Belli and I Kawachi, 2002. The macroeconomic determinants of health. Ann. Rev. Public Health, 23: 287-302.

23. Subramanian, S.V. and I. Kawachi, 2004. Income inequality and health: What have we learned so far? Epidemiol. Rev., 26: 78-91.

24. Wagstaff, A. and E. Van Doorslaer, 2000. Income inequality and health: What does the literature tell us? Ann. Rev. Public Health, 21: 543-567.

25. Waldman, R.J., 1992. Income distribution and infant mortality. Quart. J. Econom., 107: 12831302.

26. Wilkinson, R.G., 1996. Unhealthy societies: The affections of inequality. Routledge, London.

27. World Bank, 2004. World Development Indicators 2004, World Bank, Washington.

28. World Bank, 2005. World Development Indicators 2005. World Bank, Washington.

29. Pritchett, L. and L. Summers, 1996. Wealthier is healthier. The J. Human Resources, 31: 841-868.

30. Easterly, W., 1999. Life during growth. J. Econom. Growth, 4: 239-276.

31. Alsan, M., D. Bloom and D. Jamison, 2006. The consequences of population health for economic performance. Harvard University Center for Health and Wellbeing, Working Paper, : 1-27.

32. Preston, S., 1975. The changing relation between mortality and level of economic development. Population Studies, 29: 231-248.

33. Deaton, A., 2006. Global patterns of income and wealth: Facts, interpretations and policies. WIDER Annual Lecture, Helsinki, : 1-38. 